of Melbourne; I. Clunies-Ross, chairman of C.S.I.R.O., Melbourne ; Prof. T. M. Cherry, professor of mathematics, University of Melbourne; Prof. L. G. Huxley. professor of physics in the University of Adelaide : Prof. E. S. Hills, professor of geology in the University of Melbourne; A. J. Nicholson, chief of the Division of Entomology, C.S.I.R.O., Canberra; Prof. L. H. Martin, professor of physics in the University of Melbourne; with Prof. H. K. Ward, chairman of A.N.R.C., as an observer. Dr. D. F. Martyn is acting as secretary pro tem.

\section{THE AMERICAN FARMER AND HIS WOODLANDS}

\section{Forestry in Farm Management}

By R. H. Westveld and the late Ralph H. Peck. Second edition, revised by $\mathrm{R}$. H. Westveld. Pp. $\mathrm{xi}+340$. (New York: John Wiley and Sons, Inc.; London: Chapman and Hall, Ltd., 1951.) $40 s$, net.

LTHOUGH I have not had the good fortune to A visit the United States and its forest areas, I feel that an intimate knowledge of American forestry practice is not necessary in order to recognize the merits of this admirable book. If there was a British version (and how valuable it would be), it could well be renamed "Forestry in Estate Management", since this book would appear to have more in common with estate forestry in Great Britain than with farm woodlands as we know them over here.

Judging from the advice offered to American readers, it would seem that there are many aspects of private woodland management which are common to both countries. The effect of the Second World War, the need for efficient utilization, the absorption of certain types of woodland produce (such as fencing material) by the grower on his own property, the Christmas tree market, and the need for proper records and accounting, are only a few examples.

The first chapter deals with the relationship between agriculture and forestry, the contribution which forestry can make to food production, and the reason why forestry fails to do so in some cases. The figures quoted are, of course, in respect of the United States. The next two chapters are concerned with what may be described as the elements of forestry, the choice of species, site requirements, how a tree grows, even-aged and uneven-aged woods, and density and methods of propagation, being some of the points which are considered.

The problem of damage by natural and artificial causes, and the steps to be taken in combating them, are covered by parts of the third and fourth chapters. The greater portion of the fourth chapter deals, however, with forest management. Under this heading, particular attention is directed to the need for improving immature and partially stocked areas ; both these matters are often the concern of foresters in Great Britain to-day. Thinning and pruning are also considered in this chapter. It is interesting to observe that, although natural regeneration and 'selection cutting', 'group-selection cutting' and 'shelterwood cutting' are dealt with, no reference is made to sylvicultural systems as such. Doubtless the authors thought that it was unnecessary for their readers to delve too deeply into these matters.
Chapter 5 is devoted to planting and refers, inter alia, to planting compared to direct seeding, to pure and mixed stands, to the choice of young stock and to spacing. On the subject of methods of planting it is interesting to see that the method known in Britain as 'pit-planting' is referred to as 'hole-planting', and 'notch-planting' as 'slit-planting'. The remarks on planting machines are particularly interesting, since this equipment has not yet appeared in Britain to any general extent. The type described has a planting capacity of approximately ten thousand trees per eight-hour day with a crew of two. If a man plants by hand 500-700 trees per day under 'average' conditions, a planting machine will show an eight- or nine-fold increase, which is a very substantial amount. The cost of the machines varies from 200 to 750 dollars (approximately $£ 70-250$ ). As regards planting costs, a formula for ascertaining these is given, and it is added that costs vary from 6 to 30 dollars per acre (£2-10) including the trees. Even allowing for wide spacing, cheap trees, and without rabbit netting, such as we have to erect in Britain, these figures seem very low. Without netting, costs in Britain are seldom less than $£ 25$ per acre, and with netting may well be $£ 40$ per acre for small areas.

The following four chapters deal with measurement and utilization, including felling and extraction, marketing, conversion and preservation. Chapter 11 covers three special forest products : Christmas trees, rosin and turpentine (known in the United States as 'naval stores'), and maple sugar. This is followed by a chapter on the preservation of wild-life in forestry. Finally, two chapters are added covering 'forest plans' and records, and State aid to woodland owners. There are eight valuable appendixes on various subjects.

The book is well illustrated, with some excellent line drawings ; but the quality of the photographs is not up to the standard one would expect. The text includes adequate headings, and is well tabulated. This book should be of great value in the United States, and is bound to be of much interest to anyone in Britain who wishes to increase and broaden his knowledge of forestry. N. D. G. JAMES

\section{A STUDY IN CULTURE CONTACT}

From Black to White in South Australia

By Ronald and Catherine Berndt. Pp. $313+5$ plates. (Melbourne: F. W. Cheshire Pty., Ltd. ; London: Angus and Robertson, Ltd., 1951.) 37s. $6 d$.

WITH few exceptions, the effects of European domination on any of the simpler native societies are fairly predietable--a period of mutual hostility, distrust and misunderstanding, the breakdown of the traditions, ties and sanctions that held the indigenous culture together, a further period of 'drifting' and general social maladjustment, and, finally, the very gradual absorption of the subordinate people into the lower strata of European society. Depending mainly on the cultures involved, this process may be accomplished with varying degrees of difficulty; but the history of Colonial development shows that it never has been, and perhaps never can be, entirely painless for the native peoples concerned. 